\title{
Achieving a Cure: The Next Frontier in Hepatitis B Treatment
}

\author{
Tina Boortalary ${ }^{1}$ Brianna Shinn ${ }^{1,2} \bullet$ Dina Halegoua-DeMarzio ${ }^{1,2} \bullet$ \\ Hie-Won Hann ${ }^{1,2}$ \\ ${ }^{1}$ Department of Medicine, Thomas Jefferson University Hospital, Philadelphia, PA, USA; \\ ${ }^{2}$ Division of Gastroenterology and Hepatology, Department of Medicine, Thomas Jefferson \\ University Hospital, Philadelphia, PA, USA
}

Author for correspondence: Hie-Won Hann, Division of Gastroenterology and Hepatology, Department of Medicine, Thomas Jefferson University Hospital, Philadelphia, PA, USA. Email: hie-won.hann@jefferson.edu

Doi: https://doi.org/10.36255/exonpublications.livercancer.2021.ch6

\begin{abstract}
Since the discovery of the hepatitis B virus (HBV) by Blumberg et al. in 1965, significant progress has been made in understanding the pathogenesis of the virus and creating an effective vaccine. In the past two decades, several antiviral therapies have reduced the incidence of HBV-related hepatocellular carcinoma. The nucleos(t)ide analogues have succeeded in decreasing the viral load to undetectable levels but have been unable to eradicate the virus due to the persistence of covalently closed circular DNA in the hepatocyte nucleus. Despite being on successful antiviral therapy for multiple years, patients are still at risk of developing hepatocellular carcinoma. Recently, a number of different drug targets have been identified that intervene on the viral replication cycle or host immune system. This chapter discusses the immunopathogenesis of the virus, the effectiveness of nucleos(t)ide analogues, and recent therapeutic developments. In light of robust progress achieved in antiviral therapy, the cure for hepatitis B is likely on the horizon.
\end{abstract}

Keywords: cccDNA; chronic hepatitis B; hepatocellular carcinoma; hepatitis B treatment; hepatitis B virus

In: Liver Cancer. Sergi CM. (Editor). Exon Publications, Brisbane, Australia. ISBN: 978-0-6450017-2-3; Doi: https://doi.org/10.36255/exonpublications.livercancer.2021

Copyright: The Authors.

License: This open access article is licenced under Creative Commons Attribution-NonCommercial 4.0 International (CC BY-NC 4.0) https://creativecommons.org/licenses/by-nc/4.0/ 


\section{INTRODUCTION}

Despite the discovery of an effective vaccine approximately 40 years ago, hepatitis B remains an important public health concern and cause of liver-related morbidity and mortality. Over 250 million people are carriers of the virus, and nearly one million deaths occur yearly from complications of cirrhosis and hepatocellular carcinoma (HCC) (1). Although there is currently no cure for the hepatitis B virus (HBV), significant progress has been made in understanding its pathogenesis and hepatocarcinogenesis. This has paved the way for the development of therapies that have decreased the incidence of HBV-associated HCC significantly.

Our understanding of HBV began in 1965 when Blumberg and colleagues identified a new and unknown antigen in the blood sample of an Australian aborigine, subsequently named the "Australia (AU) antigen" $(2,3)$. This antigen reacted with an antibody in the serum of a transfusion-dependent patient with hemophilia. Furthermore, the AU antigen was found to be present in the donor's blood, which caused hepatitis in the recipient. This observation confirmed the antigen to be responsible for post-transfusion hepatitis. The AU antigen later became known as the Hepatitis B surface antigen (HBsAg). In 1970, Dane et al., using electron microscopy, identified the whole virus particle, which was later named the "Dane particle" $(4,5)$. In 1972, Magnius et al. identified another soluble viral protein and named it "hepatitis B e antigen (HBeAg) (6). They found that the presence of HBeAg increased the risk for transmission of the virus. Initial studies made the serologic diagnosis of hepatitis B possible and paved the way for more rigorous virologic investigation that ultimately led to the creation of the first vaccine. For his work on hepatitis B, Blumberg received the Nobel Prize in Medicine in 1976. Furthermore, Blumberg and his colleague Millman at the Fox Chase Cancer Center in Philadelphia hypothesized that HBsAg would be able to provoke an immune response and protect patients from hepatitis B. This finding was the basis for the creation of the first plasma vaccine, Heptavax B, in 1982 by Maurice Hilleman and his group at Merck. Heptavax B was derived from the blood of infected individuals (7). There was concern that viral pathogens could be transmitted through the vaccine in the era of HIV/AIDS and "non-A, non-B" hepatitis. Ultimately, this led to the development of a second vaccine in 1986 using recombinant DNA technology. The next generation vaccine was created by utilizing yeast cells for the transcription of surface antigen coding sequences (8). It was the first vaccine to use recombinant DNA methods and is still used today.

The recombinant vaccines are highly effective, protecting against chronic hepatitis B at a rate of $94-98 \%$ for at least 20 years $(9,10)$. After vaccination, it has been shown that hepatitis B surface antibody concentrations decline dramatically to less than $10 \mathrm{mIU} / \mathrm{mL}$ in more than $50 \%$ of patients within $5-10$ years (11-14). Despite the decrease of anti-HBs over time, studies have shown that a primary series of hepatitis B vaccine remains effective in preventing infection for more than 20 years $(15,16)$.

In 1992, the World Health Organization (WHO) recommended that countries integrate hepatitis B vaccine into their national immunization schedules by 1997 (17). The hepatitis B vaccine was named by the WHO as the first "cancer vaccine" given its ability to prevent HBV-associated HCC. Due to the knowledge that patients infected with hepatitis B have a $14-45 \%$ risk of developing 
HBV- associated HCC, the hepatitis vaccine has been one of the greatest achievements in public health.

\section{HBV LIFE CYCLE AND IMMUNOPATHOGENESIS}

HBV is an enveloped, partially double-stranded DNA virus that is a member of the Hepadnaviridae family. The virus consists of an outer envelope, coated with HBsAg and an inner nucleocapsid composed of hepatitis B core antigen subunits. Within the nucleocapsid resides the viral genome, which is covalently crosslinked to the DNA polymerase. The genome consists of a partially doublestranded, relaxed circular (rc) DNA and contains four overlapping open reading frames (ORF) that encode viral polymerase (Pol), surface antigen, nucleocapsid, $\mathrm{X}$ proteins, and other regulatory sequences (18). The replication cycle of the virus is illustrated by Zeisel et al. and Levrero et al. (Figure 1) (19, 20). The virus uses sodium taurocholate cotransporting polypeptide (NTCP), a transmembrane transporter predominantly expressed in the liver to gain entry to the host cell (21). This receptor's normal function is to aid in bile transport in the enterohepatic circulation. After being taken in by receptor mediated endocytosis, the virions are

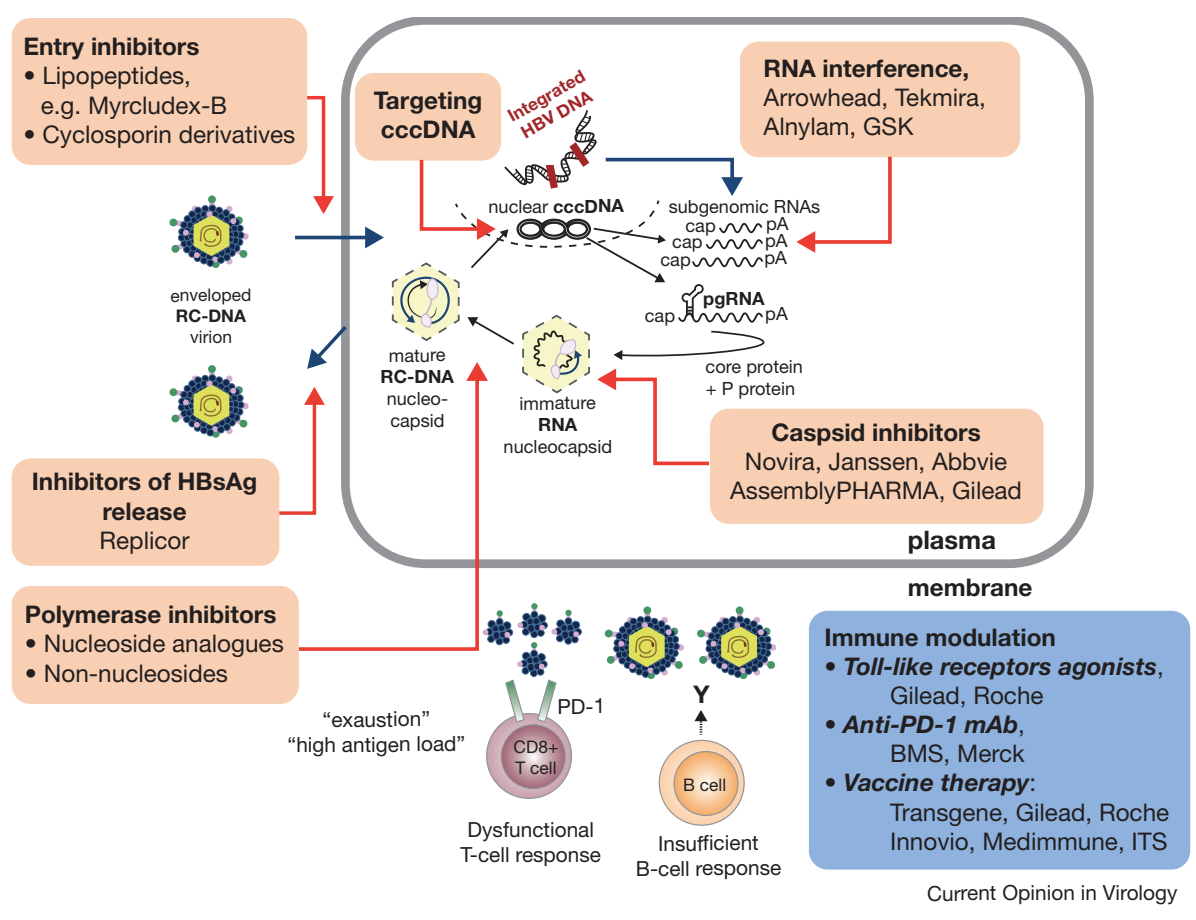

Figure 1. Hepatitis B replication cycle and potential drug targets. Adapted from Levrero et al. (20). Used with permission from original copyright holder. 
uncoated and the nucleocapsid is taken to the location of the host cell's nucleus where the rcDNA is imported through the nuclear pore into the nucleus.

The first step in replication involves the transformation of the rcDNA into a covalently, closed, circular DNA (cccDNA) mini-chromosome by host cell repair mechanisms (22). The cccDNA serves as the transcriptional template by utilizing host RNA polymerase II for the production of a four viral mRNA intermediates: a "larger-than-genome" pregenomic RNA and shorter, subgenomic transcripts. The pregenomic RNA (pgRNA) is essential for viral replication given that it serves as the template for DNA synthesis and for the translation of capsid proteins ( $\mathrm{HBcAg}$ ) and HBV DNA polymerase. Once the viral DNA polymerase is formed, it attaches to its own transcript forming the pgRNA-polymerase complex. At the same time, the core particles construct a capsid around the pgRNApolymerase complex. Within this complex, viral DNA synthesis takes place through reverse transcription and the rcDNA is formed. The shorter mRNA is translated and undergoes additional processing to form proteins that become HBV surface antigens in the viral envelope (23). In addition to forming new virions, the capsid containing rcDNA is shuttled back to the nucleus to replenish cccDNA. Therefore, sources for cccDNA include both the new entry of viral particles as well as the translocation of newly synthesized rcDNA from the cytoplasm to the nucleus (24). Even in the case of HBsAg seroconversion, the persistence of cccDNA in the nucleus is believed to cause infectivity and poses as an obstacle for cure (25).

\section{NATURAL HISTORY OF HEPATITIS B VIRUS AND CARCINOGENESIS}

HBV is not directly cytotoxic to liver cells. Liver disease is mediated through interplay of HBV replication and the host immune response. During the replication process, HBsAg is taken up and degraded by antigen presenting cells and displayed on MHC class I and class II molecules. A T-lymphocyte mediated response leads to apoptosis or release of cytokines that can down-regulate viral replication. The persistence of HBV DNA activates the host immune system leading to the chronic inflammation implicated in the development of HCC.

The connection between HBV and hepatocarcinogenesis has been firmly established since the 1980's. Although the molecular mechanisms of HBV carcinogenesis are not fully understood, it is believed to be due to a multifactorial process involving chronic liver inflammation, chromosomal instability and disruptions of cell signaling (26). Studies have shown that HBV DNA integration can lead to duplications, deletions, and chromosomal translocations of important genes that code for proteins (P53, Ras, TGF-B, Wnt/B-Catenin, cyclins A and D1) involved in cell signaling, proliferation and apoptosis $(27,28)$. The viral genotype is a risk factor for malignancy, with genotype $\mathrm{C}$ having a higher risk of causing HCC $(29,30)$. Specific mutations in pre-core regions and open reading frames coding PreS1/PreS2/S have been established as enhancers of the carcinogenic potential of HBV (29). HBV protein $X$ is thought to play an important role in regulating cellular transcription, apoptosis pathways, and cellular proliferation (31). 


\section{TREATMENT}

The goal of HBV treatment has been to reduce viral load and halt progression of liver disease leading to HCC. To date, these goals have been achieved by the use of pegylated interferon (PegIFN) and nucleos(t)ide analogues (NAs) including lamivudine, entecavir, telbivudine, adefovir, tenofovir disoproxil fumarate and tenofovir alafenamide. The exact mechanism of PegIFN is not known, however they are believed to act through immunomodulation and, to a lesser extent, by exerting a weak antiviral effect by intervening in several steps of the viral replication cycle. Unlike the NAs, PegIFN has a finite course of treatment. Its use is limited by a significant adverse effect profile, a requirement for weekly injections, and a large portion of non-responders. Lamivudine is an oral antiviral drug and was the first NA approved for the treatment of hepatitis B in 1998. Subsequently, more NAs including adefovir, entecavir, telbivudine, tenofovir disoproxil fumarate and tenofovir alafenamide became available. The best outcome expected of current antivirals is the seroconversion of HBsAg, but this clearance is only achieved in $10 \%$ of patients $(32,33)$.

\section{Prevention of HCC in patients who were treated with antiviral therapy}

While a cure for HBV infection is not available, several studies have shown a decrease of the development of HCC in patients who were treated with antiviral therapy. Liaw et al. showed that continuous treatment with lamivudine delayed clinical progression in those with chronic hepatitis B and advanced fibrosis. Patients who were assigned to receive lamivudine over placebo saw significantly lower Child-Pugh scores and decreased rates of HCC at a median duration of 32 months (34). This placebo-controlled study had to be stopped early due to the significant difference between the control and treatment groups. Hosaka et al. demonstrated that patients treated with entecavir had lower rates of HCC (3.7\%) compared to non-treated HBV patients $(13.7 \%)$ within five years $(\mathrm{p}<0.001)$. In a stratified analysis, entecavir reduced the risk of HCC four-fold in cirrhotic patients, but was not significant in those without cirrhosis (35). Kim et al. showed that HCC was decreased in those treated with tenofovir disoproxil fumarate (36).

\section{Prevention of recurrence of HCC with antiviral therapy}

Surgical resection is the preferred treatment for patients with local HCC and preserved liver function (37). Nonetheless, there is a high rate of recurrence in those with underlying chronic HBV. Persistent or high hepatitis B viral loads with or without hepatic inflammation have been associated with HCC recurrence after resection (37-39). The NAs have been widely used in patients following surgical resection or ablation of HCC. They have generally showed trends toward improved liver function and prolonged disease-free survival.

A number of studies from eastern Asia (40-44) and the US $(45,46)$ have shown a decrease in HCC recurrence and improved mortality following antiviral therapy. In 2005, Piao et al. studied outcomes in patients with HBV-related HCC 
who were treated with lamivudine. The study demonstrated that compared to an untreated, matched control group, patients with HCC who were treated with lamivudine achieved significant improvements in Child-Pugh scores at 24 months and lower mortality rates from liver failure. However, there was no change in HCC recurrence or overall survival between the two groups (40). Kuzuya et al. (41), compared outcomes in patients with HBV-related HCC who received lamivudine $(\mathrm{n}=16)$ and those who did not $(\mathrm{n}=33)$ following treatment for HCC (resection or radiofrequency ablation). The lamivudine group had better Child-Pugh scores at the time of HCC recurrence. Although there was no difference in rates of HCC recurrence or survival between the groups, patients treated with lamivudine had better remnant liver function at the time of HCC recurrence and were more likely to receive curative treatment (41). Kubo et. al. demonstrated that patients treated with lamivudine after curative resection for HBV-related HCC were more likely to have improved tumor-free survival compared to those who did not receive lamivudine treatment (43). Prolonged disease-free survival and overall survival rates were reported in another study in which patients received antiviral treatment after surgery for HBV-related HCC (44). In a large Taiwanese cohort, patients receiving NAs after liver resection were found to have lower risk of HCC recurrence and improved survival rates (42). In a two-stage longitudinal study that included a randomized clinical trial, Yin et al. also demonstrated that patients receiving NAs after surgery for HBV-related HCC had significantly decreased risk of HCC recurrence and HCC-related deaths (47). In studies from the US, Hann et al. demonstrated an increased median survival time of 80 months in patients receiving NAs for HBV-related HCC (after local tumor ablation) compared to a median survival time of 16 months in those without NA treatment $(45,46)$. Many of these studies were pooled in a meta-analysis performed by Yuan et al. and showed that the one and three-year recurrence rates of HCC and disease-free survival were significantly better in patients treated with NAs after curative treatment (liver transplant, hepatectomy, radiofrequency ablation) for HBV-related HCC (48). More recently, a study with 487 subjects demonstrated that HCC recurrence and HCC-related death were significantly decreased in patients who received antiviral treatment after hepatectomy for HCC compared to those who did not ( $\mathrm{p}=0.28, \mathrm{p}=0.004$, respectively) (49).

\section{Persistent risk for HCC despite successful HBV suppression}

Despite successful viral suppression, the risk of HCC persists even a decade after treatment. A large European study evaluated the risk factors and performance of risk scores in entecavir-treated patients. Among the 744 patients studied, 14 patients developed HCC in a median time of approximately 3 years, 12 of whom (85\%) had reached a virological response (HBV DNA level<80 IU/mL) before the diagnosis of HCC. An association between virologic suppression and HCC (HR $=0.87 ; \mathrm{p}=0.87$ ) was not observed (50). A large retrospective study from Greece showed that virologic remission, defined as undetectable DNA levels (defined as concentrations $<200 \mathrm{IU} / \mathrm{ml}$ ) did not significantly affect the incidence of HCC in all patients or those with cirrhosis (51). Despite undetectable HBV levels, HCC was noted to recur at an average of 4-5 years after treatment, especially in those with cirrhosis (52). Another study from Japan showed that 13 of 
133 patients with HBV who achieved undetectable viral levels developed HCC. They identified cirrhosis as an associated risk factor (53). It is important to recognize that "undetectable" is a relative term given the variation in measurements conducted by different laboratory assays. At the Liver Disease Prevention Center, Division of Gastroenterology and Hepatology of Thomas Jefferson University Hospital, long-term follow-up data has demonstrated HCC recurrence in patients even after a decade of successful viral suppression $(54,55)$ In our observational cohort, as of October 2020, 17 patients developed HCC despite having been treated for 9-19 years (median 13 years) with undetectable HBV DNA for 3-12 years (median 8 years) (Table 1). This is among the longest known follow up studies on the development of HCC in patients taking antiviral therapy. Recurrence of HCC has also been noted after the treatment of the initial tumor despite successful viral suppression. We have observed six patients who, after first HCC treatment, started antiviral therapy which led to successful HBV suppression for years (5-11 years) and yet developed subsequent new or recurrent HCC (Figure 2). Li et al. compared patients who received NA treatment (lamivudine with or without adefovir, $\mathrm{n}=43$ ) after hepatectomy for advanced HCC and those who did not receive NAs $(n=36)(56)$. There was no difference in the recurrence rate of HCC or disease-free survival between treatment group and control. Kuzuya et al. also found that the recurrence rates of HCC were not decreased after the administration of nucleotide analogues, but more favorable Child-Pugh scores were observed at the time of HCC reoccurrence (41).

\section{ARE WE CLOSE TO ACHIEVING HBV CURE?}

The currently available NAs target the reverse transcription of HBV RNA and have been proven to delay progression to cirrhosis. However, despite their success in halting inflammation in the liver, the risk of HCC has persisted. As demonstrated in Figure 1, NAs suppress HBV replication at one point in the cycle, but do not eliminate the cccDNA, which remains in the hepatocytes. There are currently a number of clinical trials, summarized in Table 2, that strategize different approaches to eradicating HBV (57). Each drug targets a specific point of the viral replication cycle or acts indirectly on the host immune functions. Targets can interfere with replication through the following mechanisms: (i) inhibition of viral entry; (ii) blocking rcDNA entry into the hepatic nucleus; (iii) prevention of cccDNA formation; (iv) prevention of mRNA transcription; (v) inhibition of capsid formation; (vi) inhibition of reverse transcription; and (vii) inhibition of HBV release into circulation.

\section{Entry inhibitors}

Blocking HBV entry into the hepatocyte can prevent the earliest step of infection. This is the target of Bulevirtide or formally known as Myrcludex B. The drug works by inhibiting attachment of viral pre-S1 protein to NTCP, therefore blocking the mechanism for entry (58). It has been approved by the European Commission as the first drug effective for hepatitis D and hepatitis B co-infection. 


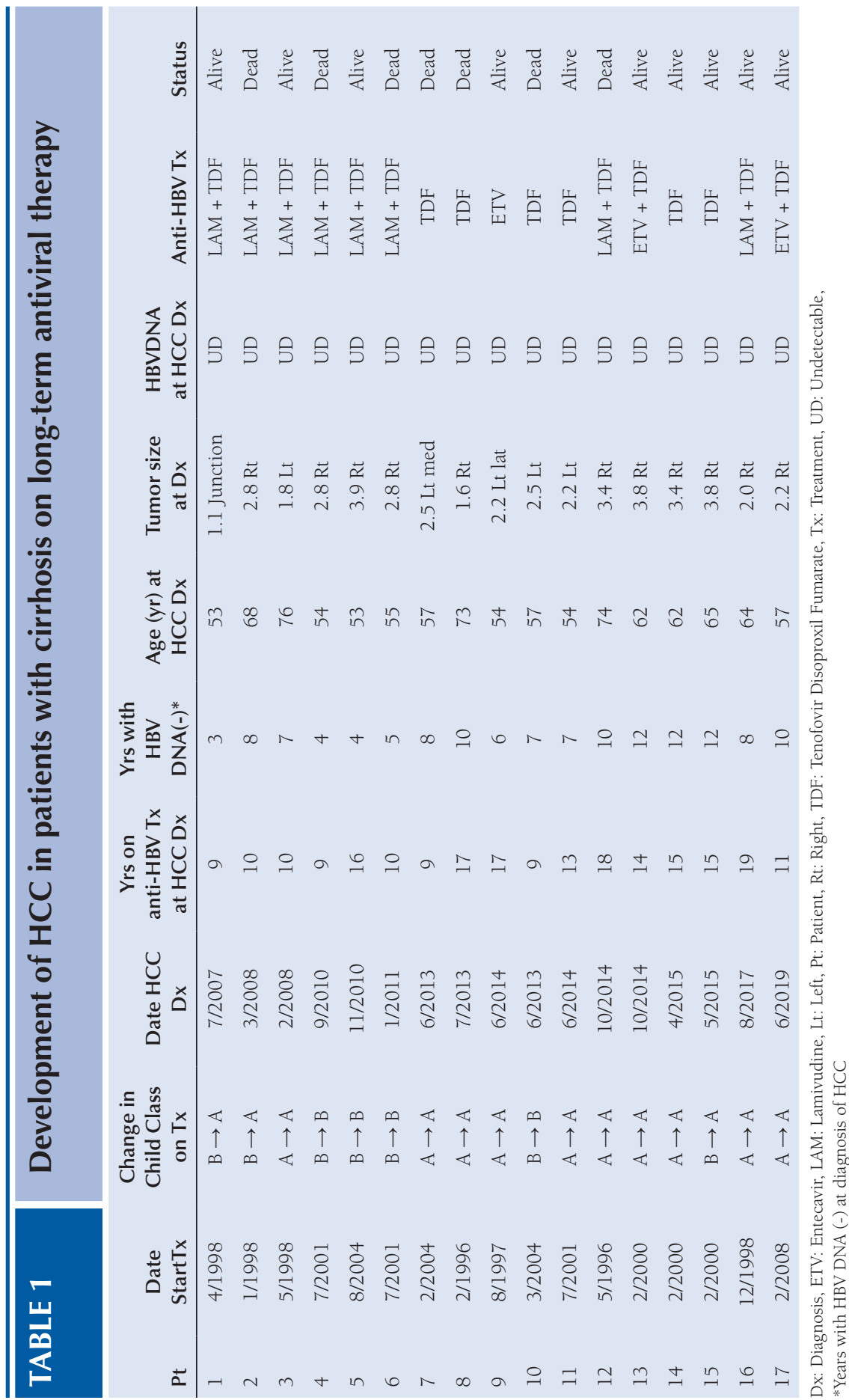




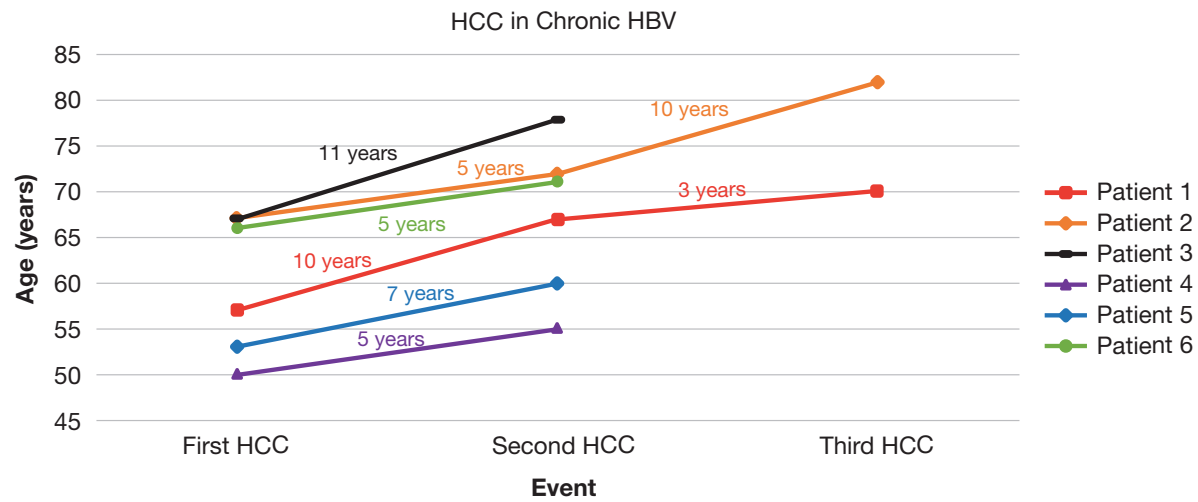

Figure 2. Development of subsequent new and recurrent HCC while on successful antiviral treatment. Graph of 6 patients demonstrates long duration time between initial and subsequent HCC diagnoses.

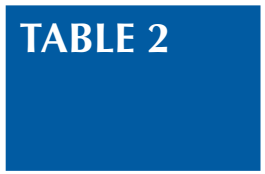

\section{Different compounds in development for treatment of hepatitis B-adapted from Hepatitis B Foundation (57)}

\begin{tabular}{lc}
\multicolumn{2}{c}{ Hepatitis B Cure Watch } \\
\hline Direct Acting Antivirals & Phase of Trial \\
\hline Entry Inhibitors (Bulevirtide) & II \\
Silencing RNA (siRNA) & Preclinical, I, II \\
Capsid or Core Inhibitors & Preclinical, I, II \\
Reverse Transcriptase Inhibitors & Approved, I, III \\
HBsAg Inhibitors & I, II \\
Indirect Acting Antivirals & Phase of Trial \\
\hline Therapeutic Vaccines & Preclinical, I, II \\
Innate Immune Defense Pathway & I, II \\
Host Acting Pathway & I, II \\
Gene Editing & Preclinical
\end{tabular}

Phase 2 data has shown that there is a reduction of viral HDV RNA after bulevirtide when combined with tenofovir or peg-interferon- $\alpha(59,60)$.

\section{Small interfering RNAs}

Small interfering RNAs (siRNAs) exhibit their effect by binding and interfering with mRNA transcripts. Because the HBV has overlapping reading frame, siRNAs are an appealing approach to eliminate multiple different proteins (61). There are several agents at various points in clinical trials. ARC-520 was an earlier siRNA 
developed against HBV, which showed reductions of serum HBsAg concentrations when given as monthly injections with oral entecavir in HBeAg positive patients. There was less of a reduction in HBeAg-negative patients (62). This was likely because the drug targeted cccDNA-derived pgRNA, the source of HBsAg in HBeAg-positive patients and not the integrated HBV DNA seen in HBeAg-negative patients (63). JNJ-3989 and AB-729 were second-generation siRNAs that showed reductions of HBsAg regardless of HBeAg positivity (64-66).

\section{Capsid inhibitors}

HBV core protein is necessary for capsid formation, genome packaging and delivery of rcDNA into the nucleus. Therefore, core inhibitors or core modulators disrupt the viral lifecycle by inducing the assembly of defective capsids or capsids that lack genetic material. By this mechanism, they are thought to intervene on multiple points of the lifecycle, even targeting cccDNA by causing its destabilization and preventing its replenishment. There are several different classes of core protein assembly modulators (CpAMs) including phenylpropenamide which have normal morphologies but lack genetic material (empty capsids) and hetero-aryl-dihydropyrimidines (HAP) derivatives, which have aberrant morphologies (67). The first compound studied in humans in phase $1 \mathrm{~b}$ study was NVR3-778. It showed a 1-2 log reduction in HBV DNA levels but no change in HBsAg levels until the drug was combined with peg-IFN (68).

Core inhibitors are the first viral specific compounds that are capable of targeting cccDNA. A recent phase 2 study (69) demonstrated that ABI-H0731, a core protein inhibitor, not only interfered with viral capsid formation and entry of rcDNA into the nucleus, but also decreased levels of pgRNA. In that study, the combination of the ABI-H0731 and entecavir showed greater reductions of viral DNA load and pgRNA levels by week 24 in treatment naive, HBeAg+, individuals compared to entecavir alone $(\mathrm{p}=0.0452)$. When patients were switched from entecavir to the combination of both, they saw immediate decline in HBV DNA and pgRNA levels (Figure 3). By week 48, the mean HBV DNA and pgRNA levels declined 6.3 logs and 3.0 logs from baseline, respectively. The accelerated decline after the addition of ABI-H0731 was attributed to the reductions in the cccDNA pool, the only known source of HBV pgRNA (70).

\section{Reverse transcriptase inhibitors}

NAs act by interfering with synthesis of viral DNA from pgRNA. Currently six NAs are available for treatment of HBV. As synthetic compounds, they resemble endogenous nucleosides that are incorporated into growing DNA strands during replication. They halt DNA synthesis and terminate chain elongation by inhibiting reverse transcriptase (71). Besifovir dipivoxil maleate, a novel drug in this class was approved for use in Korea after phase III trials (72). It has been shown to have antiviral efficacy comparable to that of tenofovir disoproxil fumarate (TDF) after 48 weeks of treatment and has been associated with reduced bone and renal toxicities (73). Lipid conjugates of TDF are also in development and have been shown to increase activity against HBV and have a better safety profile (74). 

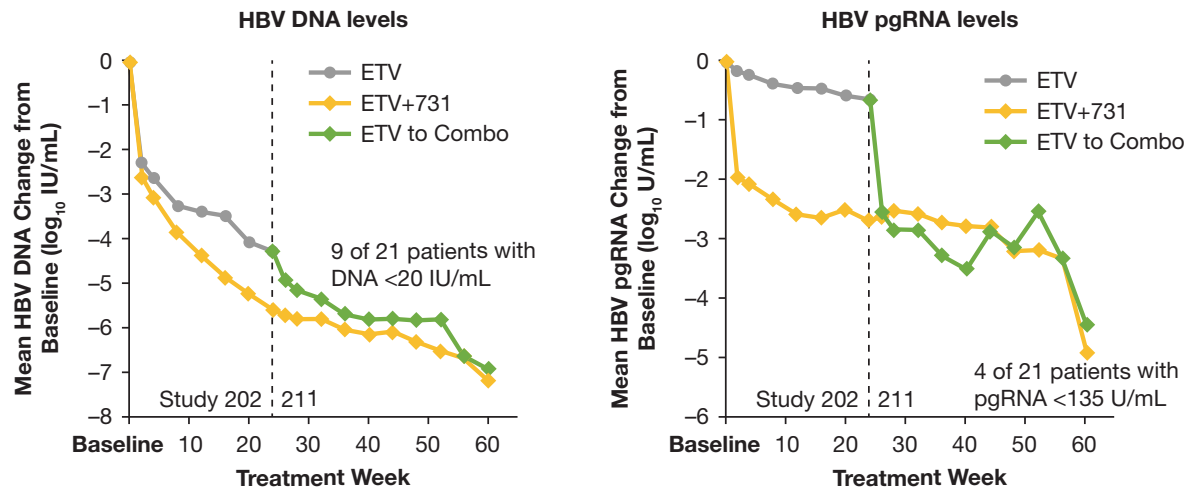

Figure 3. Study 202 and 211 results of Entecavir alone, Entecavir+ABI-H0731 (Core Protein Inhibitor), and switch from entecavir to combo on HBV DNA levels and pgRNA levels. Adapted from Sulkowski et al. (70). Used with permission. The combination of the ABI-H0731 and entecavir showed greater reductions of viral DNA load and pgRNA levels by week 24 in treatment naïve, $\mathrm{HBeAg}+$, individuals compared to entecavir alone $(p=0.0452)$. When patients were switched from entecavir to the combination of both, they saw immediate decline in HBV DNA and pgRNA levels.

\section{HBsAg inhibitors}

HBsAg release inhibitors interfere with the production of HBsAg, which is needed for the virus to enter and leave the liver cell. Most of viral antigen in the blood is HBsAg and circulating levels are almost entirely made of HBV subviral particles (SVP). These small particles are produced independently of viral replication and are non-infectious. However, it has been suggested that SVPs can neutralize antibodies to the virus and suppress other aspects of host immune function $(75,76)$. The nucleic acid polymer (NAP), REP 2139 , is a synthetic RNA that is taken up by hepatocytes and suppresses the production of SVPs derived from integrated HBV DNA or cccDNA. A phase 2 randomized control trial showed that the addition of NAPs to TDF and pegIFN allowed significantly more patients to achieve HBsAg levels below $1 \mathrm{IU} / \mathrm{mL}$ and HBsAg seroconversion (77). Another method by which HBsAg is inhibited is through interruption in the intracellular re-localization of the protein to the Golgi apparatus. This is the mechanism utilized by Benzimidazole, BM601, which decreases HBsAg and HBV release (78).

\section{cccDNA inhibitors}

Directly inhibiting cccDNA would be the optimal HBV therapy, but aside from the capsid inhibitor (ABI-H0731) that has shown promising results, no drugs have shown to target cccDNA in clinical trials (79). Potential mechanisms to target cccDNA may involve inhibiting its formation, transfer into the nucleus, conversion to cccDNA, or transcription after cccDNA is produced. Several gene-editing technologies utilize site-specific nucleases to cleave HBV DNA. The zinc finger nucleases (ZFNs), transcription activator-like effector nucleases 
(TALENs) and clustered regularly interspaced short palindromic repeats (CRISPR/ Cas system) have been developed to interrupt cccDNA in vitro (75). After a specific coding sequence is matched with the desired segment of DNA, a doublestranded break is made in the genetic material. The host cell's DNA repair machinery is used to repair the DNA, introducing mutations that render the gene ineffective (80). Although the field of gene editing is exciting, a lot of work needs to be done to eliminate "off target" effects and improve delivery of the large compounds.

\section{Antivirals targeting host immunity}

Immune modulation of the host's innate and adaptive immune responses is another area of interest in HBV therapeutic research. Vaccine technology that aids in treatment rather than prevention is sought. These new vaccines seek to generate HBV specific T cells responses. However, results have not been very promising. Toll-Like Receptor agonists are being developed to help recognize the virus and produce cytokines necessary for activating the innate immune system (81). Checkpoint inhibitors used in the field of oncology are also being investigated for the treatment of HBV. They are targeted against proteins such as programmed cell death protein 1 (PD-1)/programmed death-ligand 1 (PD-L1), and block inhibition of T-cells and restore their activity in recognizing antigens (82). Another category of therapeutics targets cellular inhibitor of apoptosis proteins (cIAPs). cIAPs diminish TNF-signaling and apoptosis during hepatitis B infection, leading to the persistence of infected hepatocytes and HBV (83).

\section{CONCLUSION}

While significant advancements have been made regarding the understanding of immunopathogenesis and management of hepatitis B, no curative treatment for hepatitis B exists. Furthermore, the virus has been shown to re-emerge and cause significant mortality even at undetectable levels. The ultimate goal of the new therapies will be to eradicate cccDNA from hepatocytes. The cure for the virus will likely rely on the combination of multiple therapies, targeting different aspects of the replication cycle. With the recent advances in drug development, the treatment for hepatitis B may be very different in the near future.

Conflict of interest: The authors declare no potential conflicts of interest with respect to research, authorship and/or publication of this chapter.

Copyright and permission statement: The authors confirm that the materials included in this chapter do not violate copyright laws. Where relevant, appropriate permissions have been obtained from the original copyright holder(s), and all original sources have been appropriately acknowledged or referenced. 


\section{REFERENCES}

1. Tsai K-N, Kuo C-F, Ou J-HJ. Mechanisms of hepatitis B virus persistence. Trends Microbiol. 2018;26(1):33-42. https://doi.org/10.1016/j.tim.2017.07.006

2. Blumberg BS, Alter HJ. A new antigen in leukemia sera. Jama. 1965;191(7):541-6. https://doi. org/10.1001/jama.1965.03080070025007

3. Blumberg BS. Australia antigen and the biology of hepatitis B. Science. 1977;197(4298):17-25. https://doi.org/10.1126/science.325649

4. Dane DS, Cameron CH, Briggs M. Virus-like particles in serum of patients with Australia-antigenassociated hepatitis. Lancet. 1970;1(7649):695-8. https://doi.org/10.1016/S0140-6736(70)90926-8

5. Yuen MF, Chen DS, Dusheiko GM, Janssen HLA, Lau DTY, Locarnini SA, et al. Hepatitis B virus infection. Nat Rev Dis Primers. 2018;4:18035. https://doi.org/10.1038/nrdp.2018.35

6. Magnius LO, Espmark JÅ. New specificities in Australia antigen positive sera distinct from the Le Bouvier determinants. J Immunol. 1972;109(5):1017-21.

7. Szmuness W, Stevens CE, Harley EJ, Zang EA, Oleszko WR, William DC, et al. Hepatitis B vaccine: demonstration of efficacy in a controlled clinical trial in a high-risk population in the United States. NEJM. 1980;303(15):833-41. https://doi.org/10.1056/NEJM198010093031501

8. Valenzuela P, Medina A, Rutter WJ, Ammerer G, Hall BD. Synthesis and assembly of hepatitis B virus surface antigen particles in yeast. Nature. 1982;298(5872):347-50. https://doi.org/10.1038/298347a0

9. Chen D-S. Hepatitis B vaccination: the key towards elimination and eradication of hepatitis B. J Hepatol. 2009;50(4):805-16. https://doi.org/10.1016/j.jhep.2009.01.002

10. Ni YH, Huang LM, Chang MH, Yen CJ, Lu CY, You SL, et al. Two decades of universal hepatitis B vaccination in Taiwan: impact and implication for future strategies. Gastroenterology. 2007;132(4):1287-93. https://doi.org/10.1053/j.gastro.2007.02.055

11. Goh KT, Oon C, Heng B, Lim G. Long-term immunogenicity and efficacy of a reduced dose of plasma-based hepatitis B vaccine in young adults. Bulletin of the World Health Organization. 1995;73(4):523-7.

12. Wainwright RB, Bulkow LR, Parkinson AJ, Zanis C, McMahon BJ. Protection provided by hepatitis B vaccine in a Yupik Eskimo population-results of a 10-year study. J Infect Dis. 1997;175(3):674-7. https://doi.org/10.1093/infdis/175.3.674

13. Gold Y, Somech R, Mandel D, Peled Y, Reif S. Decreased immune response to hepatitis B eight years after routine vaccination in Israel. Acta Paediatrica. 2003;92(10):1158-62. https://doi. org/10.1111/j.1651-2227.2003.tb02477.x

14. Mahawal B, Bhai N, Kataria V, Gulati N, Chandola I. Estimation of Anti Hbs antibody titer in adults during 5-10 years period following three doses of vaccine. IOSR J Pharm Biol Sci. 2013;7(1):20-3. https://doi.org/10.9790/3008-0712023

15. Poovorawan Y, Chongsrisawat V, Theamboonlers A, Bock HL, Leyssen M, Jacquet J-M. Persistence of antibodies and immune memory to hepatitis B vaccine 20 years after infant vaccination in Thailand. Vaccine. 2010;28(3):730-6. https://doi.org/10.1016/j.vaccine.2009.10.074

16. Mendy M, Peterson I, Hossin S, Peto T, Jobarteh ML, Jeng-Barry A, et al. Observational study of vaccine efficacy 24 years after the start of hepatitis B vaccination in two Gambian villages: no need for a booster dose. Plos One. 2013;8(3):e58029. https://doi.org/10.1371/journal.pone.0058029

17. Shepard CW, Simard EP, Finelli L, Fiore AE, Bell BP. Hepatitis B virus infection: epidemiology and vaccination. Epidemiol Rev. 2006;28(1):112-25. https://doi.org/10.1093/epirev/mxj009

18. Kato H, Sugiyama M, Mizokami M. Hepatitis B Virus Genotypes. In: Liaw Y-F, Zoulim F, editors. Hepatitis B Virus in Human Diseases. Cham: Springer International Publishing; 2016. p. 63-78. https://doi.org/10.1007/978-3-319-22330-8_3

19. Zeisel MB, Lucifora J, Mason WS, Sureau C, Beck J, Levrero M, et al. Towards an HBV cure: state-of-theart and unresolved questions-report of the ANRS workshop on HBV cure. Gut. 2015;64(8):1314-26. https://doi.org/10.1136/gutjnl-2014-308943

20. Levrero M, Testoni B, Zoulim F. HBV cure: why, how, when? Curr Opin Virol. 2016;18:135-43. https://doi.org/10.1016/j.coviro.2016.06.003 
21. Yan H, Zhong G, Xu G, He W, Jing Z, Gao Z, et al. Sodium taurocholate cotransporting polypeptide is a functional receptor for human hepatitis B and D virus. Elife. 2012;1:e00049. https://doi. org/10.7554/eLife.00049

22. Wong DJ, Locarnini SA. Molecular Virology and Life Cycle. In: Kao J-H, Chen D-S, editors. Hepatitis B Virus and Liver Disease. Singapore: Springer Singapore; 2018. p. 1-23. https://doi. org/10.1007/978-981-10-4843-2_1

23. Trépo C, Chan HL, Lok A. Hepatitis B virus infection. Lancet. 2014;384(9959):2053-63. https://doi. org/10.1016/S0140-6736(14)60220-8

24. Mahtab M-A. Liver: A Complete Book on Hepato-Pancreato-Biliary Diseases-E-Book: Elsevier Health Sciences; 2012.

25. Morikawa K, Suda G, Sakamoto N. Viral life cycle of hepatitis B virus: Host factors and druggable targets. Hepatol Res. 2016;46(9):871-7. https://doi.org/10.1111/hepr.12650

26. Fernández-Rodríguez CM, Gutiérrez-García ML. Prevention of hepatocellular carcinoma in patients with chronic hepatitis B. World J Gastrointest Pharmacol Ther. 2014;5(3):175-82. https://doi. org/10.4292/wjgpt.v5.i3.175

27. Boyault S, Rickman DS, de Reynies A, Balabaud C, Rebouissou S, Jeannot E, et al. Transcriptome classification of HCC is related to gene alterations and to new therapeutic targets. Hepatology. 2007;45(1):42-52. https://doi.org/10.1002/hep.21467

28. Tan YJ. Hepatitis B virus infection and the risk of hepatocellular carcinoma. World J Gastroenterol. 2011;17(44):4853-7. https://doi.org/10.3748/wjg.v17.i44.4853

29. Yang HI, Yeh SH, Chen PJ, Iloeje UH, Jen CL, Su J, et al. Associations between hepatitis B virus genotype and mutants and the risk of hepatocellular carcinoma. J Natl Cancer Inst. 2008;100(16):1134-43. https://doi.org/10.1093/jnci/djn243

30. Chan HL, Hui AY, Wong ML, Tse AM, Hung LC, Wong VW, et al. Genotype C hepatitis B virus infection is associated with an increased risk of hepatocellular carcinoma. Gut. 2004;53(10):1494-8. https://doi.org/10.1136/gut.2003.033324

31. Bouchard MJ, Schneider RJ. The enigmatic X gene of hepatitis B virus. J Virol. 2004;78(23):12725-34. https://doi.org/10.1128/JVI.78.23.12725-12734.2004

32. Gish RG, Given BD, Lai C-L, Locarnini SA, Lau JY, Lewis DL, et al. Chronic hepatitis B: virology, natural history, current management and a glimpse at future opportunities. Antiviral Res. 2015;121:47-58. https://doi.org/10.1016/j.antiviral.2015.06.008

33. Zoulim F, Durantel D. Antiviral therapies and prospects for a cure of chronic hepatitis B. Cold Spring Harb Perspect Med 5: a021501. 2015. https://doi.org/10.1101/cshperspect.a021501

34. Liaw Y-F, Sung JJ, Chow WC, Farrell G, Lee C-Z, Yuen H, et al. Lamivudine for patients with chronic hepatitis B and advanced liver disease. N Engl J Med. 2004;351(15):1521-31. https://doi. org/10.1056/NEJMoa033364

35. Hosaka T, Suzuki F, Kobayashi M, Seko Y, Kawamura Y, Sezaki H, et al. Long-term entecavir treatment reduces hepatocellular carcinoma incidence in patients with hepatitis B virus infection. Hepatology. 2013;58(1):98-107. https://doi.org/10.1002/hep.26180

36. Kim W, Berg T, Loomba R, Schall RA, Dinh P, Yee L, et al. 43 long term tenofovir disoproxil fumarate (tdf) therapy and the risk of hepatocellular carcinoma. J Hepatol. 2013;58:S19. https://doi. org/10.1016/S0168-8278(13)60045-8

37. Wu JC, Huang YH, Chau GY, Su CW, Lai CR, Lee PC, et al. Risk factors for early and late recurrence in hepatitis B-related hepatocellular carcinoma. J Hepatol. 2009;51(5):890-7. https://doi.org/10.1016/j. jhep.2009.07.009

38. Hung IF, Poon RT, Lai CL, Fung J, Fan ST, Yuen MF. Recurrence of hepatitis B-related hepatocellular carcinoma is associated with high viral load at the time of resection. Am J Gastroenterol. 2008;103(7):1663-73. https://doi.org/10.1111/j.1572-0241.2008.01872.x

39. Kim BK, Park JY, Kim DY, Kim JK, Kim KS, Choi JS, et al. Persistent hepatitis B viral replication affects recurrence of hepatocellular carcinoma after curative resection. Liver Int. 2008;28(3):393-401. https://doi.org/10.1111/j.1478-3231.2007.01625.x

40. Piao CY, Fujioka S, Iwasaki Y, Fujio K, Kaneyoshi T, Araki Y, et al. Lamivudine treatment in patients with HBV-related hepatocellular carcinoma--using an untreated, matched control cohort. Acta Med Okayama. 2005;59(5):217-24. 
41. Kuzuya T, Katano Y, Kumada T, Toyoda H, Nakano I, Hirooka Y, et al. Efficacy of antiviral therapy with lamivudine after initial treatment for hepatitis B virus-related hepatocellular carcinoma. J Gastroenterol Hepatol. 2007;22(11):1929-35. https://doi.org/10.1111/j.1440-1746.2006.04707.x

42. Wu CY, Chen YJ, Ho HJ, Hsu YC, Kuo KN, Wu MS, et al. Association between nucleoside analogues and risk of hepatitis B virus-related hepatocellular carcinoma recurrence following liver resection. JAMA. 2012;308(18):1906-14. https://doi.org/10.1001/2012.jama.11975

43. Kubo S, Tanaka H, Takemura S, Yamamoto S, Hai S, Ichikawa T, et al. Effects of lamivudine on outcome after liver resection for hepatocellular carcinoma in patients with active replication of hepatitis B virus. Hepatol Res. 2007;37(2):94-100. https://doi.org/10.1111/j.1872-034X.2007.00013.x

44. Chan AC, Chok KS, Yuen WK, Chan SC, Poon RT, Lo CM, et al. Impact of antiviral therapy on the survival of patients after major hepatectomy for hepatitis B virus-related hepatocellular carcinoma. Arch Surg. 2011;146(6):675-81. https://doi.org/10.1001/archsurg.2011.125

45. Hann HW, Bergin D, Coben R, DiMarino AJ. Prevention of new hepatocellular carcinoma with concomitant antiviral therapy in chronic hepatitis B patients whose initial tumor was successfully ablated. Int J Cancer. 2011;128(3):739-42. https://doi.org/10.1002/ijc.25382

46. Hann HW, Coben R, Brown D, Needleman L, Rosato E, Min A, et al. A long-term study of the effects of antiviral therapy on survival of patients with HBV-associated hepatocellular carcinoma (HCC) following local tumor ablation. Cancer Med. 2014;3(2):390-6. https://doi.org/10.1002/ cam4.197

47. Yin J, Li N, Han Y, Xue J, Deng Y, Shi J, et al. Effect of antiviral treatment with nucleotide/nucleoside analogs on postoperative prognosis of hepatitis B virus-related hepatocellular carcinoma: a two-stage longitudinal clinical study. J Clin Oncol. 2013;31(29):3647-55. https://doi.org/10.1200/ JCO.2012.48.5896

48. Yuan P, Chen P, Qian Y. Evaluation of Antiviral Therapy Performed after Curative Therapy in Patients with HBV-Related Hepatocellular Carcinoma: An Updated Meta-Analysis. Can J Gastroenterol Hepatol. 2016;2016:5234969. https://doi.org/10.1155/2016/5234969

49. Zhang X, Li C, Wen T, Yan L, Yang J, Tang H, et al. The Different Effects of Nucleotide and Nucleoside Analogues on the Prognosis of HBV-Related HCC After Curative Resection. J Gastrointest Surg. 2020. https://doi.org/10.1007/s11605-020-04633-3

50. Arends P, Sonneveld MJ, Zoutendijk R, Carey I, Brown A, Fasano M, et al. Entecavir treatment does not eliminate the risk of hepatocellular carcinoma in chronic hepatitis B: limited role for risk scores in Caucasians. Gut. 2015;64(8):1289-95. https://doi.org/10.1136/gutjnl-2014-307023

51. Papatheodoridis GV, Manolakopoulos S, Touloumi G, Vourli G, Raptopoulou-Gigi M, VafiadisZoumbouli I, et al. Virological suppression does not prevent the development of hepatocellular carcinoma in HBeAg-negative chronic hepatitis B patients with cirrhosis receiving oral antiviral(s) starting with lamivudine monotherapy: results of the nationwide HEPNET. Greece cohort study. Gut. 2011;60(8):1109-16. https://doi.org/10.1136/gut.2010.221846

52. Yoo J, Hann HW, Coben R, Conn M, DiMarino AJ. Update Treatment for HBV Infection and Persistent Risk for Hepatocellular Carcinoma: Prospect for an HBV Cure. Diseases. 2018;6(2).27 https://doi. org/10.3390/diseases6020027

53. Ando Y, Ishigami M, Ishizu Y, Kuzuya T, Honda T, Hayashi K, et al. Cumulative incidence and risk factors for the development of hepatocellular carcinoma in patients with chronic hepatitis $\mathrm{B}$ who achieved sustained disappearance of viremia by nucleos(t)ide analog treatment. Hepatol Res. 2018;48(3):E240-E51. https://doi.org/10.1111/hepr.12976

54. Shinn BJ, Kristler C, Roth C, Hann HW. Need For HBV Cure: Persistent Risk For Subsequent New And Recurrent HCC Even After A Decade Of Successful Anti-HBV Therapy And Initial Tumor Ablation. Arch Cancer Res. 2018;6:1-6. https://doi.org/10.21767/2254-6081.100172

55. Shinn BJ, Martin A, Coben RM, Conn MI, Prieto J, Kroop H, et al. Persistent risk for new, subsequent new and recurrent hepatocellular carcinoma despite successful anti-hepatitis B virus therapy and tumor ablation: The need for hepatitis B virus cure. World J Hepatol. 2019;11(1):65-73. https://doi. org/10.4254/wjh.vll.il.65

56. Li N, Lai EC, Shi J, Guo W-X, Xue J, Huang B, et al. A comparative study of antiviral therapy after resection of hepatocellular carcinoma in the immune-active phase of hepatitis B virus infection. Ann Surg Oncol. 2010;17(1):179-85. https://doi.org/10.1245/s10434-009-0694-z 
57. Compounds in Development for Chronic Hepatitis B Doylestown, PA Hepatitis B Foundation September 22, 2020. Available from: https://www.hepb.org/treatment-and-management/drug-watch/.

58. Kang C, Syed YY. Bulevirtide: First Approval. Drugs. 2020;80(15):1601-5. https://doi.org/10.1007/ s40265-020-01400-1

59. Wedemeyer H, Bogomolov P, Blank A, Allweiss L, Dandri-Petersen M, Bremer B, et al. Final results of a multicenter, open-label phase $2 \mathrm{~b}$ clinical trial to assess safety and efficacy of Myrcludex B in combination with Tenofovir in patients with chronic HBV/HDV co-infection. J Hepatol. 2018;68:S3. https:// doi.org/10.1016/S0168-8278(18)30224-1

60. Wedemeyer H, Schoeneweis K, Bogomolov PO, Voronkova NV, Chulanov V, Stepanova T, et al., editors. Interim results of a multicentre, open-label phase 2 clinical trial (MYR203) to assess safety and efficacy of Myrcludex B in combination with Peg-Interferon alpha 2a in patients with chronic HBV/ HDV co-infection. J Hepatol. 2019;70(1):E81 https://doi.org/10.1016/S0618-8278(19)30141-0

61. Lopatin U. Drugs in the Pipeline for HBV. Clin Liver Dis. 2019;23(3):535-55. https://doi.org/10.1016/j. cld.2019.04.006

62. Yuen M-F, Liu K, Given B, Schluep T, Hamilton J, Lai C, et al. RNA interference therapy with ARC520 Injection results in long term off-therapy antigen reductions in treatment naïve, HBeAg positive and negative patients with chronic HBV. J Hepatol. 2018;68:S526. https://doi.org/10.1016/ S0168-8278(18)31302-3

63. Nguyen MH, Wong G, Gane E, Kao J-H, Dusheiko G. Hepatitis B virus: advances in prevention, diagnosis, and therapy. Clin Microbiol Rev. 2020;33:e00046-19 https://doi.org/10.1128/CMR.00046-19

64. Yuen R, Locarnini S, Lim TH, Strasser S, Sievert W, Cheng W, et al. Short term RNA interference therapy in chronic hepatitis B using JNJ-3989 brings majority of patients to HBsAg< $100 \mathrm{IU} / \mathrm{ml}$ threshold. J Hepatol. 2019;70(1):E51-E52 https://doi.org/10.1016/S0618-8278(19)30092-1

65. Lee AC, Thi EP, Cuconati A, Ardzinski A, Holland R, Huang H, et al. FRI-184-Function and drug combination studies in cell culture models for AB-729, a subcutaneously administered siRNA investigational agent for chronic hepatitis B infection. J Hepatol. 2019;70(1):e471. https://doi.org/10.1016/ S0618-8278(19)30929-6

66. Martinez MG, Villeret F, Testoni B, Zoulim F. Can we cure hepatitis B virus with novel direct-acting antivirals? Liver Int. 2020;40:27-34. https://doi.org/10.1111/liv.14364

67. Revill P, Locarnini S. The Basis for Antiviral Therapy: Drug Targets, Cross-Resistance, and Novel Small Molecule Inhibitors. In: Liaw Y-F, Zoulim F, editors. Hepatitis B Virus in Human Diseases. Cham: Springer International Publishing; 2016. p. 303-24. https://doi.org/10.1007/978-3-319-22330-8_14

68. Yuen MF, Gane EJ, Kim DJ, Weilert F, Chan HLY, Lalezari J, et al. Antiviral activity, safety, and pharmacokinetics of capsid assembly modulator NVR 3-778 in patients with chronic HBV infection. Gastroenterology. 2019;156(5):1392-403. e7. https://doi.org/10.1053/j.gastro.2018.12.023

69. Hann H. Are we Close to Achieving HBV Cure? Risk for Hepatocellular Carcinoma Persists De-spite Successful Suppression of Hepatitis B Virus for Over a Decade. JPN J Gastroenterol Hepatol. 2020;3(2):1-5.

70. Sulkowski M, Agarwal K, Fung S, Yuen M-F, Ma X, Lalezari J, et al. Continued therapy with ABIH0731+ NrtI results in sequential reduction/loss of HBV DNA, HBV RNA, HBeAg, HBcrAg and HBsAg in HBeAg-positive patients. Hepatology. 2019;70(6):1486A-7A.

71. Davis GL, Pawlotsky, JM. Current and Future Therapy for Hepatitis B and C. In: Arias IM (Ed). The Liver. John Wiley \& Sons, West Sussex, UK 2009. p. 899-919.

72. Yim HJ, Kim W, Ahn SH, Yang JM, Jang JY, Kweon YO, et al. Besifovir Dipivoxil Maleate 144Week Treatment of Chronic Hepatitis B: An Open-Label Extensional Study of a Phase 3 Trial. Am J Gastroenterol. 2020;115(8):1217-25. https://doi.org/10.14309/ajg.0000000000000605

73. Ahn SH, Kim W, Jung YK, Yang JM, Jang JY, Kweon YO, et al. Efficacy and Safety of Besifovir Dipivoxil Maleate Compared With Tenofovir Disoproxil Fumarate in Treatment of Chronic Hepatitis B Virus Infection. Clin Gastroenterol Hepatol. 2019;17(9):1850-9 e4.

74. Dawood A, Abdul Basit S, Jayaraj M, Gish RG. Drugs in Development for Hepatitis B. Drugs. 2017;77(12):1263-80. https://doi.org/10.1007/s40265-017-0769-2

75. Peters MG, Locarnini S. New direct-acting antiviral agents and immunomodulators for hepatitis $B$ virus infection. Gastroenterol Hepatol. 2017;13(6):348-56. 
76. Rydell GE, Prakash K, Norder H, Lindh M. Hepatitis B surface antigen on subviral particles reduces the neutralizing effect of anti-HBs antibodies on hepatitis B viral particles in vitro. Virology. 2017;509:67-70. https://doi.org/10.1016/j.virol.2017.05.017

77. Bazinet M, Pântea V, Placinta G, Moscalu I, Cebotarescu V, Cojuhari L, et al. Safety and efficacy of 48 weeks REP 2139 or REP 2165, tenofovir disoproxil, and pegylated interferon alfa-2a in patients with chronic HBV infection naive to nucleos(t)ide therapy. Gastroenterology. 2020;158(8):2180-94 https://doi.org/10.1053/j.gastro.2020.02.058

78. Xu Y-B, Yang L, Wang G-F, Tong X-K, Wang Y-J, Yu Y, et al. Benzimidazole derivative, BM601, a novel inhibitor of hepatitis B virus and HBsAg secretion. Antiviral Res. 2014;107:6-15. https://doi. org/10.1016/j.antiviral.2014.04.002

79. Yang Y-C, Chen Y-H, Kao J-H, Ching C, Liu I-J, Wang C-C, et al. Permanent inactivation of HBV genomes by CRISPR/Cas9-mediated non-cleavage base editing. Mol Ther Nucleic Acids. 2020; 20:480-90 https://doi.org/10.1016/j.omtn.2020.03.005

80. Zhu A, Liao X, Li S, Zhao H, Chen L, Xu M, et al. HBV cccDNA and its potential as a therapeutic target. J Clin Transl Hepatol. 2019;7(3):258-62. https://doi.org/10.14218/JCTH.2018.00054

81. Ma Z, Cao Q, Xiong Y, Zhang E, Lu M. Interaction between Hepatitis B Virus and Toll-Like Receptors: Current Status and Potential Therapeutic Use for Chronic Hepatitis B. Vaccines (Basel). 2018;6(1).6. https://doi.org/10.3390/vaccines6010006

82. Feray C, Lopez-Labrador FX. Is PD-1 blockade a potential therapy for HBV? JHEP Rep. 2019;1(3):142-4. https://doi.org/10.1016/j.jhepr.2019.07.007

83. Liu H, Hou J, Zhang X. Targeting cIAPs, a New Option for Functional Cure of Chronic Hepatitis B Infection? Virologica Sinica. 2018;33(5):459-61. https://doi.org/10.1007/s12250-018-0062-x 
